\title{
Assessment of Knowledge, Attitude and Practice of Adults in Jeddah about Food Interaction
}

\author{
ALBRAA SUMEER S ABUALHAMAIL ${ }^{1,2}$, MAHA SALEH H ALJDANI ${ }^{1,2}$, \\ SARAH SALEH H ALJDANI ${ }^{1,2}$, NOOR ABDULRHMAN UTHMAN ALAMOUDI, \\ ASIA OMAR ALGHAMDI ${ }^{1,2}$, SUHAD M BAHIJRI ${ }^{2,3,4}$, GHADA MA AJABNOOR ${ }^{2,3,4}$ \\ and HANAN JAMB| $\left.\right|^{2,3,5}$
}

\author{
${ }^{1}$ Faculty of Medicine, King AbdulAziz University, Jeddah, Saudi Arabia. \\ ${ }^{2}$ Food and Nutrition Research Unit, ${ }^{3}$ Saudi Diabetes Research Group, King Fahd Medical Research \\ Center, King Abdulaziz University, Jeddah, Saudi Arabia. \\ ${ }^{4}$ Department of Clinical Biochemistry, Faculty of Medicine, King AbdulAziz University, \\ Jeddah, Saudi Arabia. \\ ${ }^{5}$ Department of Food and Nutrition- Home Economics, King Abdulaziz University, Jeddah, Saudi Arabia. \\ *Corresponding author E-mail: sbahijri@gmail.com
}

http://dx.doi.org/10.12944/CRNFSJ.4.3.02

(Received: October 31, 2016; Accepted: November 25, 2016)

\begin{abstract}
Cultural beliefs and practices, and improper use of medications of Saudis may be associated with poor nutritional status. to assess knowledge, attitude and practice of Saudi adults regarding possible effects of selected food combinations, and effects of medications on nutritional status, in association with gender, age and educational level. A questionnaire was constructed to include demographic information, some food combinations culturally avoided, or scientifically known to adversely affect nutritional status, possible interactions of food with medications, sources of information, and personal experience of adverse affects following certain food combinations. Subjects were recruited from public areas to complete the questionnaire. An electronic version was distributed through social network. A total of 998 questionnaires were completed, with $60.9 \%$ females, $66.5 \%$ $\leq 25$ years of age, and $75.6 \%$ having university degree. Women, and subjects with $\geq$ secondary school education had significantly higher knowledge score $(P=0.007$, and 0.01 respectively). The majority of participants did not know food combinations that can adversely affect nutritional status, especially those having < secondary school certificate. Significantly higher proportion of subjects > 40 years of age believed in traditional taboos $(P=0.038)$. Attitude was affected by gender. Hearsay and media were major sources of information, with higher percentage of females intentionally seeking knowledge. Nutritional knowledge is poor among Saudis, with folklore, and media being main sources. This might contribute to the increased prevalence of nutrition related diseases. Nutrition education programmes should be introduced early in life through different channels.
\end{abstract}

Keywords: Assessment questionnaire, Nutritional Knowledge,

Food combinations, food-food interactions, drug-food interactions.

\section{INTRODUCTION}

Micronutrients deficiencies are still quite common globally, even in developed and affluent countries $^{1,2}$. In particular, deficiencies in iron, iodine, vitamin $\mathrm{A}$, folate and zinc can have devastating consequences. At least half of children worldwide ages 6 months to 5 years suffer from one or more micronutrient deficiency, and globally more than 2 billion people are affected ${ }^{3}$. Saudi Arabia is no exception, with reports of various forms of anemia; including iron and folate deficiencies ${ }^{4-6}$, zinc deficiency $\left.{ }^{7}\right]$ vitamin $A^{8-10}$, and vitamin $D^{11}$. ${ }^{13}$ deficiencies, and iodine deficiency ${ }^{14}$ found in literature. Unavailability of food, or eating an unbalanced diet that does not contain all nutrients necessary for good nutritional status are the immediate causes of nutritional deficiencies. 
In addition, social factors and cultural practices in most countries have a very great influence on what people eat, on how they prepare and combine various food types, on their feeding practices and on the foods they prefer, hence adequacy of their diet.Indeed, some traditional food practices and taboos in some societies may contribute to nutritional deficiencies among particular groups of the population.

Food combining is one of the primary factors that can affect digestion, and absorption of various nutrients; thus; altering their bioavailability, and hence the irassimilation ${ }^{15}$. Therefore, commonly used; or avoided; food combinations in a community could be either deleterious or beneficial to nutritional status. Furthermore, population groups with higher nutrient requirements, such as infants, adolescents, and pregnant and lactating women, may be more sensitive to nutrient- nutrient interactions ${ }^{16}$. In addition, many commonly prescribed medications can interfere with the body's ability to absorb and utilize nutrients ${ }^{17}$. Nutritionists need to have a knowledge of the food habits, practices, and taboos of the communities in which they work so that they can help to reinforce the positive habits as well as strive to change any negative ones.Knowledge of drug/nutrient, and food- food interaction, including common food combinations used, or avoided in the community has not been previously studied in Saudi Arabia. Therefore, the aim of this study was to assess the knowledge of Saudi adults; randomly selected from Jeddah residents; about the possible effects of selected food combinations on nutritional status, as well as the effects of medications on nutrients bioavailability and metabolism. In addition, their source of information, and their attitude towards possible food or nutrient interactions, as well as the possible influence of gender, age and educational level were investigated.

Table 1: Questions testing knowledge of food/ food and drug / food interactions, and their answers

1. Do you think that mixing between specific types of food can affect health?

Yes

2. Do you think that eating honey with fruits can cause symptoms of ill health?

3. Do you think that eating seafood with fruits can cause symptoms of ill health?

No

No

4. Do you think that eating red meat with fruits can cause symptoms of ill health?

No

No

5. Do you think that eating fish with dairy products can cause symptoms of ill health?

Yes

6. Do you think that eating dairy products with leafy vegetables and/or whole grains

Yes

7. Do you think that drinking tea after a meal of iron-rich food (such as meat or legumes) can affect its nutritional value?

8. Do you think that eating fish with eggs can cause symptoms of ill health?

No

9. Do you think that eating seafood with yellow melon can cause symptoms of ill health? No

10. Do you think that genetic factors determine the extent of experienced effects of Yes food-food interactions?

11. Do you think that aging determines the extent of experienced effects of food-food interactions?

12. Do you think that overweight and obesity determine the extent of experienced

effects of food-food interactions?

13. Do you think that sleep disturbance determine the extent of experienced

effects of food-food interactions?

14. Do you think that the time during menstrual cycle determine the extent of

Yes

No

No

experienced effects of food-food interactions?

15. Do you think that medications can affect nutrients bioavailability and metabolism?

16. Do you think that food combinations can affect the efficacy of medications?
No

Yes

Yes 


\section{MATERIALS AND METHODS}

A short list of food combinations commonly believed to cause discomfort or disease; hence tabooed; as well as beliefs regarding the effect of physiological variables, and medications on expected effects, was collected from various local sources, including: folklore, social network and personal contacts. This was incorporated intoa questionnaire constructed in clear Arabic, which also included the food - food interactions scientifically known to have negative effects on nutritional status (such as tea with iron containing foods, and phytate or oxalate rich foods with dairy products), sources of information (folklore and religious beliefs, hearsay, and unreliable sources, versus accredited sources), and questions on personal experience of adverse affects caused by certain food combinations or food- food interactions (symptoms, action taken, and effect on future dietary practices), in addition to demographic information on age, gender and educational attainment. The questionnaire was tested for clarity on 100 adult men and women aged 18- 75 years. The final version of the questionnaire; in addition to demographic information (3 questions), consisted of 23multiple choice or true and false questions divided into:, knowledge (16 questions- Table 1), sources of knowledge, and previous experience with food- food interaction as well as ways of coping with it (7 questions)(Table 2). A score out of 16 was given to the knowledge section. The research was approved by "the Committee on the Ethics of Human Research" at King Abdulaziz University, Jeddah, Saudi Arabia.

A cross sectional design was employed to recruit a convenience sample of apparently healthy men and women aged $\geq 18$ years from the general adult population in public areas such as malls and waiting areas in hospitals during the period April 1, 2013 to March31, 2014 . Willing subjects were asked to complete the designed questionnaire. In addition an electronic version was distributed through social network.

Table 2: Questions testing experience and attitude about food/ food and drug / food interactions, and indicating source of knowledge

\section{Questions \\ Given Choices}

1. Have you ever mixed between any foods commonly believed to cause ill health including the previously mentioned types of food?

2. Did you suffer from apparent symptoms of ill health following your experience?

3. Which type of symptoms did you experience?

4. How did you get rid of the symptoms?

5. Did you stop mixing these types of food later on? 6. What is your usual source of information regarding food/ food and drug / food interactions?
a)Yes b)No

a) Yes b)No

a) General feeling of discomfort, and un-wellness b)Gl disturbances, c)Skin manifestations, d) others - More than one choice can be picked a)Resting and waiting, b) Self medication by taking laxatives or traditional herbal remedies,

c) Seeing a doctor or going to hospital,

d) other measures - More than one choice can be picked

a) Yes b)No

a)Religious teachings, b)School or college,

c) The media, d)Friends and social contacts,

e) Reading books, f) Browsing the internet, g)Family physician, h)Dietician, i) Health organizations, j) personal experience

- More than one choice can be picked 


\section{Statistical Analysis}

The collected data were reviewed, coded, entered and analyzed using Statistical Package of Social Science (SPSS) software; version 20.0.

Continuous variables were presented as mean values \pm standard deviation, while qualitative variables were presented as absolute frequencies and relative frequencies (percentages).

Contingency tables with calculation of chi-square test were used to evaluate association between categorical variables to assess the significance in the differences between proportions. On the other hand, the significance in the differences between means was assessed using independent Samples student $t$ test for dichotomous nominal variables. All presented P-values were two-tailed and taken at a significance level of 0.05 and $95 \%$ Confidence Interval.

\section{RESULTS}

Valid returned forms were 998 questionnaires, with 608 or $60.9 \%$ of total filled by females.

Demographic characteristics of participants are presented in table 3.
The majority of subjects (66.5\%) were in the youngest age group, with less than $10 \%$ falling in the above 40 years category, butthe distribution between age groups was significantly different between males and females, with a higher than expected percentage of females in the youngest age group, and lower percentage than expected in the other two age groups. In addition, most of the participants (75.6\%) had at least a university degree. However, there was a significant gender difference in the distribution between different educational attainment categories, with a higher than expected percentage of females having less than secondary school certificate, and lower than expected percentage having secondary school certificate, oruniversity degree.

\section{Evaluation of Knowledge}

The mean score of participants in the knowledge section was 12.5 , with a standard deviation of 1.83 , and 559 ( $56 \%$ of total) havingan above average score (>12.5). Women had a significantly higher mean score (13.4), compared to men (12.1) ( $P=0.007)$. Educational attainment also had a significant effect on overall score $(P=0.01)$, with only $42.4 \%$ of participants with < secondary school qualifications had above an average score, compared to $56.9 \%$ for those with $\geq$ secondary school

Table 3: Demographic characteristics of participating males and females

\begin{tabular}{|c|c|c|c|c|c|}
\hline & $\begin{array}{l}\text { Males } \\
\mathrm{N}=390\end{array}$ & $\begin{array}{l}\text { Females } \\
\mathrm{N}=608\end{array}$ & $\begin{array}{l}\text { Total } \\
\mathrm{N}=998\end{array}$ & $P$ Value & \\
\hline \multirow[t]{2}{*}{$\begin{array}{l}\text { Age } \\
\text { categories }\end{array}$} & $\begin{array}{l}18-25 \\
\text { yrs } \\
26-40\end{array}$ & $\begin{array}{l}244 \\
(62.6 \%) \\
113\end{array}$ & $\begin{array}{l}420 \\
(69.1 \%) \\
147\end{array}$ & $\begin{array}{l}664 \\
(66.5 \%) \\
260\end{array}$ & 0.007 \\
\hline & $\begin{array}{l}\text { yrs } \\
>40 \\
\text { yrs }\end{array}$ & $\begin{array}{l}(29.0 \%) \\
33 \\
(8.5 \%)\end{array}$ & $\begin{array}{l}(24.2) \\
41 \\
(6.7 \%)\end{array}$ & $\begin{array}{l}(26.1 \%) \\
74 \\
(7.4 \%)\end{array}$ & \multirow{4}{*}{0.009} \\
\hline \multirow[t]{3}{*}{$\begin{array}{l}\text { Educational } \\
\text { attainments }\end{array}$} & $\begin{array}{l}<\text { Secondary } \\
\text { school }\end{array}$ & $\begin{array}{l}12 \\
(3.1 \%)\end{array}$ & $\begin{array}{l}47 \\
(7.7 \%)\end{array}$ & $\begin{array}{l}59 \\
(5.9 \%)\end{array}$ & \\
\hline & $\begin{array}{l}\text { Secondary } \\
\text { school }\end{array}$ & $\begin{array}{l}76 \\
(19.5 \%)\end{array}$ & $\begin{array}{l}108 \\
(17.8 \%)\end{array}$ & $\begin{array}{l}184 \\
(18.4 \%)\end{array}$ & \\
\hline & $\begin{array}{l}\text { >Bachelor } \\
\text { degree }\end{array}$ & $\begin{array}{l}302 \\
(77.4 \%)\end{array}$ & $\begin{array}{l}453 \\
(74.5 \%)\end{array}$ & $\begin{array}{l}755 \\
(75.6 \%)\end{array}$ & \\
\hline
\end{tabular}


certificate. However, there was no significant effect due to age $(P=0.378)$, with $56.2 \%$ of participants $\leq$ 40 years of age obtaining above an average score, compared to $54.1 \%$ for the older group.

Considering responses to individual knowledge questions, the outcome was different. The majority of responders (849 subjects - $85 \%$ of sample) acknowledged the existence of foodfood interaction, and that it could be beneficial or deleterious to health, and/ or nutritional status (question 1- Table 1), with no significant difference between men and women (Figure 1a), nor between different age groups. However, educational level had a significant effect $(P<0.001)$ with $22 \%$ of those having less than secondary school certificate being unaware of the fact, compared to a lower percentage of $\approx 15 \%$ in the other two groups (Figure $1 \mathrm{~b}$ ).

Furthermore, misconceptions and lack of correct conceptions about unhealthy food combinations and various interactions were wide spread of note, the finding that $62.1 \%$ of the sample did not acknowledge the existence of drug-food or food- drug interactions, and interactions scientifically proven to affect nutritional status; such as tea and iron containing foods (Question 15- Table 1); were not known by $63 \%$ of the sample, with those having $<$ secondary schoolcertificate showing even a higher percentage of $85 \%$.Similarly the effect of eating leafy vegetables and/or whole grains with dairy products (Question 6- Table 1) was unknown to $72 \%$ of the sample, with those having < secondary schoolcertificate showing even a higher percentage of $91 \%$.

Age also had a significant effect on nutritional beliefs $(P=0.038)$, with almost half

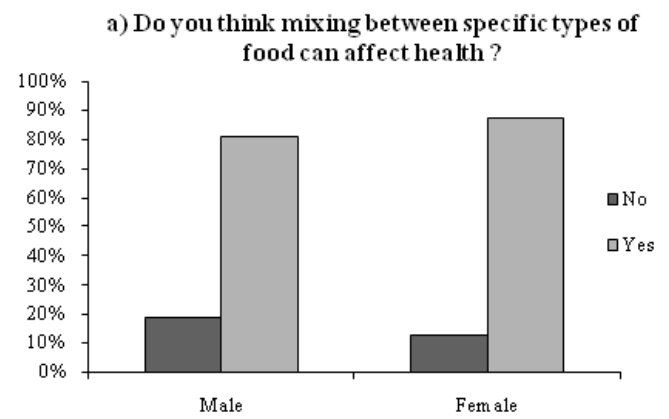

of those $>40$ years of age $(49.2 \%)$ believing in traditional taboos (Question 2-5, 8 \&9- Table 1), compared to $38.9 \%$ of the younger age groups.

\section{Evaluation of experience,attitude, and practice}

A total of 379 participant $(44.6 \%$ of total sample) answered (yes), to question 1 in Table 2, thus indicated an experience of mixing between some specific types of food, with a significantly higher proportion of men compared to women $(\mathrm{P}=$ 0.041 ), but without a significant difference between age groups. However, only 154 of them (i.e. $40.6 \%$ ) reported that they developed related ill health symptoms (Question 2- Table 2), with no significant difference between men and women, or between different age groups.

Reported symptoms varied between choice a) general symptoms (15.6\%), choice b)GI upset $(71.5 \%)$, and choice c)skin manifestations (19.9\%). However, only a very small percentage $(9.1 \%)$ of those who had developed symptoms decided to stop mixing between these types of food, with a higher proportion of females compared to males ( $P=0.047$ ), but no difference between age groups, or due to educational attainment.

Answers to methods used to alleviate symptoms (question 4-Table 2) also varied between choice a)Resting and waiting reported by $23.3 \%$ of those experiencing symptoms, choice b) Self medication by taking laxatives or traditional herbal remedies reported by $52.2 \%$, and choice c) Seeing a doctor or going to hospital reported by $24.5 \%$. Significant difference was noted between genders $(P=0.047)$, with a higher percentage of females resorting to choice $b$ ), and a higher percentage of men preferring choice a). In addition, a significantly

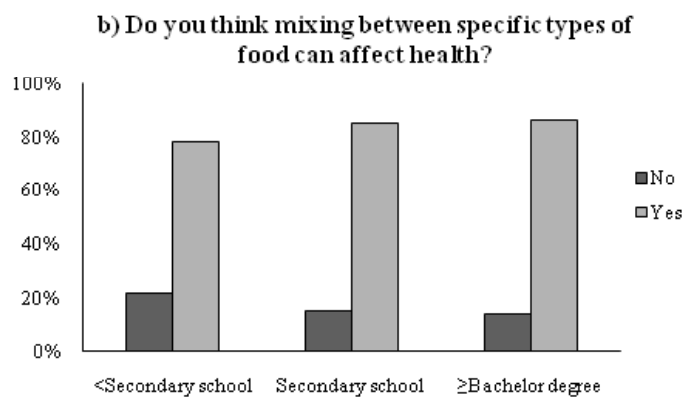

Fig. 1: The percentage of participants acknowledging food/food interaction according to a) gender, b) educational attainment 
higher percentage of participants $\leq 40$ years preferred choice c) $(\mathrm{P}=0.041)$.

Regarding the source of their knowledge, only $1.1 \%$ of participants reported obtaining their knowledge from religious teachings (choice a- in question 6), while $55 \%$ of participants ( with a significantly higher proportion of $>40$ years age group, $\mathrm{P}=0.038$ ) reported obtaining their knowledge without making a conscious effort through social talks and meeting, or an actual personal experience (choices d- and j- in question 6), while $33 \%$ of subjects (mainly $\leq 40$ years of both genders) reported making a personal unguided effort by browsing the internet (choice $f$ - in question 6), listening, watching or reading material available in the media(choice c- in question 6) (mainly females having $>$ secondary school certificate), or by reading simple books (choice d- in question 6) (mainly those having $>$ secondary school certificate). Only $12 \%$ of the participants made a conscious effort to obtain reliable information either from their own study programme (mainly females $\leq 40$ years of age), or from professional sources by asking doctors, dieticians, or from information provided by health organization(choices b-, and g- to i- in question 6) (mainly females $>40$ years of age).

\section{DISCUSSION}

The interplay of many factors determine foodrelated behavior. These include: sociodemographic (income, education and occupation), physiological, as well as behavioral and life style factors, in addition to knowledge and attitudes related to diet and health ${ }^{18,19}$.

In spite of huge development and modernization in Saudi Arabia during the last four decades, nutritional deficiencies are still encountered and documented in literature ${ }^{4-14}$. Food habits, and taboos may play a role, since food is not in shortage, and food choices have increased due to the improvement in economic status. Indeed, obesity among adults showed a progressive increase from $22 \%$ in $1990-1993^{20}$ to $36 \%$ in $2005^{21}$, andis projected to increase to $41 \%$ by 2022 in men, and to $78 \%$ in women particularly in the age groups 35-44, 45-54 and 55-64 years ${ }^{22}$. These contrasting reports strongly suggest poor nutritional knowledge, and dietary practices; including avoiding or promoting certain food combination; among Saudis. In addition to health professionals, the contributions of professionals in many other spheres are needed to evaluate causes, and suggest possible solutions to these diet related conditions. No previous studies have been conducted in our region to study food habits, as well as beliefs and taboos regarding healthy nutritional practices. Our study is the first to assess knowledge, attitude, beliefs and practice in Saudi Arabia, hoping to provide some clues to existing diet related controversies.

It is well established that components present in ingested meals may alter the mineral bioavailability in them, leading to better or poorer absorption ${ }^{15}$. For example, beverages high in polyphenol contentcan be potent inhibitors of iron absorption especially non- heam iron ${ }^{23}$, and better calcium uptake is found when taken together with oligofructose $e^{24}$.

In addition to its effect on micronutrient bioavailability, food combinations might affect the glycemic index of combination meals, hence their effect on weight as a whole, and waist circumferencein particular ${ }^{25,26}$, which in turn will have an effect on the risk of type 2 diabetes mellitus ${ }^{27}$.

Misconceptions and lack of knowledge is wide spread as seen in our results. The very common practice of drinking tea after meals might be one of the main contributors to the high prevalence of iron deficiency anemia in our community, with its associated poor work productivity and school performance. In addition, the fact that a high percentage( $62 \%$ ) of the sample did not know the truth about drug-food interaction, mightpartially explain the noted decreased efficacy of drug regimen prescribed by doctors resulting in poor control of chronic diseases such as diabetes, hypertension and dyslipidemia and reported in literature ${ }^{28-31}$.

Nutritional knowledge was affected by gender, and educational attainment, with females, and participants having $\geq$ secondary school certificate obtaining a higher mean score in knowledge section compared to males $(P=0.007)$, and participants with lower educational qualifications $(P=0.01)$ respectively. However, age affected 
certain parts of the knowledge section, with a higher percentage of participants $\geq 40$ years of age believing in traditional taboos. This is expected, since younger people are less likely to cling to tradition.

Gender differences were obvious in attitude and practice also, with a higher percentage of males admitting to mixing between foods thought to cause ill effects, and reporting that they did not stop this behavior after experiencing symptoms of ill health. On the other hand, age difference was obvious in the preference of younger age groups to consult health professional when faced with symptoms. In addition, both age and gender had an impact onsource of knowledge for participants, with the older age group obtaining their knowledge unintentionally mainly through social gathering, compared to intentional seeking for information through the media, internet, or simple books by younger generation, especially females. It was also disappointing to find that only a small percentage of participants; mainly females; resorted to professional guidance.

Our results can be explained by the fact that nutrition as a science is newly introduced to the Saudi public through the media mainly, with no formal nutrition education teaching beingcarried out in schools. At university level, it is only studied at specialized colleges for female students mainly, thus the higher awareness amongst female participants.
Moreover, females tend to be more conscious about their appearances generally; especially when they work; needing to fit in with the latest image trends. Even though this is advantageous in a way, but without adequate knowledge and professional guidance, it could lead to poor health effectsto themselves, andto their off springs as reported in literature ${ }^{32}$.

In conclusion, nutritional knowledge about food interactions is poor. Folklore is the main source. This might be a contributing factor to the increased prevalence of anemia and osteomalacia in our population. Therefore, professionally designed nutrition education programmes must be introduced early in life through school, and later through the media tomodulate food habits in order to combat nutrition related diseases. The task maybe difficult, but not impossible. Indeed, in many countries the current staple foods are not the same as those eaten even a century ago, and rice was not indigenous to the gulf countries, yet it is now the major food staple in our region.

Our study has its limitations, with method of collecting data being the main one. However, it provides information to a poorly researched area, and help to guide future nutrition education programmes.

\section{REFERENCES}

1. Micronutrient deficiencies: Iron deficiency anaemia [http://www.who.int/nutrition/topics/ ida/en/]

2. Micronutrient deficiencies: Vitamin A deficiency [http://www.who.int/nutrition/topics/ $\mathrm{vad} / \mathrm{en} /]$

3. UNICEF: Global Report.Investing in the future: A united call to action on vitamin and mineral deficiencies 2009.

4. Al-Othaimeen AKO, Sadaa Al Orf, Abdulaziz: Prevalence of nutritional anaemia among primary school girls in Riyadh City, Saudi Arabia. International journal of food sciences and nutrition, 50:237-243, 1999.

5. Al Hifzi I, Pejaver R, Qureshi I: Screening for iron deficiency anemia in a well baby clinic. Annals of Saudi medicine, 16:622-624,
1996.

6. Al Hassan NN: The prevalence of iron deficiency anemia in a Saudi University female students.Journal of Microscopy and Ultrastructure, 3:25-28, 2015.

7. Bahijri S: Serum zinc in infants and preschool children in the Jeddah area: effect of diet and diarrhea in relation to growth. Annals of Saudi medicine, 21:324-329, 2015.

8. Al Senaidy AM: Brief report. Serum concentration of retinol, $\beta$-carotene, cholesterol, and triglycerides in Saudi school children.Journal of tropical pediatrics, 46:163167, 2000.

9. Al-Saleh I, Billedo G, El-Doush I, Mohamed GE-D, Yosef G: Selenium and vitamins status in Saudi children.Clinica chimica acta, 
368:99-109, 2006.

10. Alissa EA, Bahjri SM, Al-Ama N, Ahmed WH, Starkey B, Ferns GA: Dietary vitamin A may be a cardiovascular risk factor in a Saudi population. Asia Pacific journal of clinical nutrition, 14:137, 2005.

11. Bahijri SM: Serum 25-hydroxy cholecalciferol in infants and preschool children in the Western region of Saudi Arabia. Etiological factors. Saudi medical journal, 22:973-979, 2001.

12. Sedrani S, Al-Arabi K, Abanmy A, Elidrissy A: Vitamin D status of saudis III. Prevalence of inadequate plasma 25-hydroxyvitamin D concentrations. Saudi medical journal, 13:214-219, 1992.

13. Alsuwaida AO, Farag YM, AI Sayyari AA, Mousa DH, Alhejaili FF, Al-Harib AS, Housawi AA, Mittal BV, Singh AK: Prevalence of vitamin $D$ deficiency in Saudi adults. Saudi medical journal, 34:814-818, 2013.

14. Abbag FI, Abu-Eshy SA, Mahfouz AA, Al-Fifi SA, El-Wadie H, Abdallah SM, Musa MG, Devansan CS, Patel A: lodine-deficiency disorders in the Aseer region, south-western Saudi Arabia: 20 years after the national survey and universal salt iodization. Public health nutrition, 18:2523-2529, 2015.

15. SandstroÈm B: Micronutrient interactions: effects on absorption and bioavailability. British Journal of Nutrition, 85:S181-S185, 2001.

16. Power H, Heese H, Beatty D, Hughes J, Dempster W: Iron fortification of infant milk formula: the effect on iron status and immune function. Annals of tropical paediatrics, 11:5766, 1990.

17. Bobroff LB, Lentz A, Turner RE: Food/ drug and drug/nutrient interactions: what you should know about your medications. University of Florida Cooperative Extension Service, Institute of Food and Agriculture Sciences, EDIS; 1999.

18. Hulshof K, Wedel M, Löwik M, Kok F, Kistemaker C, Hermus RJ, Ten Hoor F, Ockhuizen T: Clustering of dietary variables and other lifestyle factors (Dutch Nutritional Surveillance System). Journal of Epidemiology and Community Health 1992, 46:417-424,
1990.

19. Martinez-Gonzalez M, Lopez-Azpiazu I, Kearney J, Kearney M, Gibney M, Martinez $\mathrm{J}$ : Definition of healthy eating in the Spanish adult population: a national sample in a panEuropean survey.Public Health, 112:95-101, 1998.

20. al-Nuaim AA, Bamgboye EA, al-Rubeaan $\mathrm{KA}$, al-Mazrou Y: Overweight and obesity in Saudi Arabian adult population, role of sociodemographic variables. J Community Health, 22:211-223, 1997.

21. World Health Organization. Noncommunicable Diseases and Mental Health Cluster. Surveillance Team.: STEPS instruments for NCD risk factors (core and expanded version 1.4) : the WHO STEPwise approach to Surveillance of noncommunicable diseases (STEPS). Geneva:World Health Organization; 2001.

22. Al-Quwaidhi A, Pearce M, Critchley J, Sobngwi E, O'Flaherty M: Trends and future projections of the prevalence of adult obesity in Saudi Arabia, 1992-2022/Tendances et projections de la prévalence de l'obésité chez l'adulte en Arabie saoudite, 1992-2022. Eastern Mediterranean Health Journal, 20:589, 2014.

23. Hurrell RF, Reddy M, Cook JD: Inhibition of non-haem iron absorption in man by polyphenolic-containing beverages. British Journal of Nutrition, 81:289-295, 1999.

24. Ohta A, Ohtsuki M, Baba S, Adachi T, Sakata T, Sakaguchi E: Calcium and magnesium absorption from the colon and rectum are increased in rats fed fructo-oligosaccharides. $J$ Nutrition, 125:2417-2424, 1995.

25. Du H, van Bakel M, Slimani N, Forouhi $\mathrm{N}$, Wareham N, Halkjaer J, Tjønneland A, Jakobsen MU, Overvad K, Schulze M: Dietary glycaemic index, glycaemic load and subsequent changes of weight and waist circumference in European men and women. International journal of obesity, 33:12801288, 2009.

26. Romaguera D, Ängquist L, Du H, Jakobsen MU, Forouhi NG, Halkjær J, Feskens EJ, Masala G, Steffen A, Palli D: Dietary determinants of changes in waist circumference adjusted for 
body mass index-a proxy measure of visceral adiposity. PLos one, 5:e11588, 2010.

27. Sakurai M, Nakamura K, Miura K, Takamura T, Yoshita K, Morikawa Y, Ishizaki M, Kido T, Naruse Y, Suwazono Y: Dietary glycemic index and risk of type 2 diabetes mellitus in middle-aged Japanese men.Metabolism, 61:47-55, 2012.

28. Khattab M, Khader YS, Al-Khawaldeh A, Ajlouni K: Factors associated with poor glycemic control among patients with type 2 diabetes. Journal of diabetes and its complications, 24:84-89, 2010.

29. AISaggaf W, Asiri M, Ajlan B, Afif AB, Khalil $R$, Salman AB, Alghamdi A, Bashawieh $O$, Alamoudi A, Aljahdali A: Reported Benefits of Insulin Therapy for Better Glycemic Control in Type 2 Diabetic Patients-Is This Applicable in Saudi Patients? Clinical Medicine Insights
Endocrinology and Diabetes, 9:13, 2016.

30. Saeed AA, Al-Hamdan NA, Bahnassy AA, Abdalla AM, Abbas MA, Abuzaid LZ: Prevalence, awareness, treatment, and control of hypertension among Saudi adult population: a national survey.International journal of hypertension, 2011:135-174, 2011.

31. Alavudeen SS, Dhanapal C, Khan NA, AI Akhali KM, Paulliah SD: Prevalence and control of cardiovascular risk factors among type 2 diabetes mellitus patients in southern region of Saudi Arabia.Journal of Young Pharmacists, 5:144-147, 2013.

32. Pugliese MT, Weyman-Daum M, Moses N, Lifshitz F: Parental health beliefs as a cause of nonorganic failure to thrive.Pediatrics, 80:175-182, 1987. 